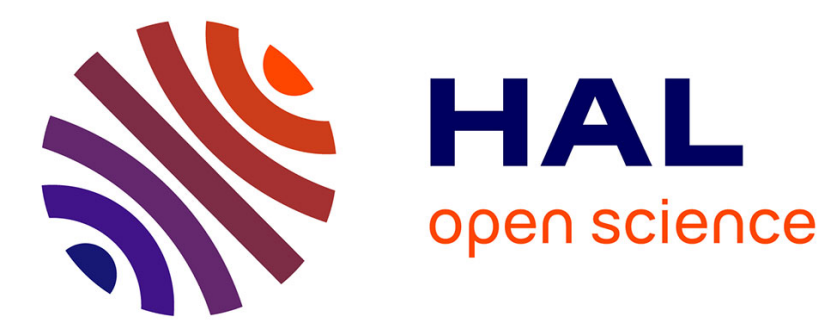

\title{
Electrical properties of MOS radiation dosimeters
}

Gérard Sarrabayrouse, A. Bellaouar, P. Rossel

\section{To cite this version:}

Gérard Sarrabayrouse, A. Bellaouar, P. Rossel. Electrical properties of MOS radiation dosimeters. Revue de Physique Appliquée, 1986, 21 (4), pp.283-287. 10.1051/rphysap:01986002104028300 . jpa00245443

\section{HAL Id: jpa-00245443 https://hal.science/jpa-00245443}

Submitted on 1 Jan 1986

HAL is a multi-disciplinary open access archive for the deposit and dissemination of scientific research documents, whether they are published or not. The documents may come from teaching and research institutions in France or abroad, or from public or private research centers.
L'archive ouverte pluridisciplinaire HAL, est destinée au dépôt et à la diffusion de documents scientifiques de niveau recherche, publiés ou non, émanant des établissements d'enseignement et de recherche français ou étrangers, des laboratoires publics ou privés. 
Classification

Physics Abstracts

73.60D

\title{
Electrical properties of MOS radiation dosimeters
}

\author{
G. Sarrabayrouse, A. Bellaouar and P. Rossel \\ Laboratoire d'Automatique et d'Analyse des Systèmes du C.N.R.S., 7, Avenue du Colonel Roche, \\ 31077 Toulouse Cedex, France
}

(Reçu le 5 novembre 1985, révisé le 17 décembre, accepté le 23 décembre 1985)

\begin{abstract}
Résumé. - Des transistors MOS sont utilisés comme dosimère de rayonnement. La sensibilité obtenue couvre la gamme $20 \mathrm{mV} / \mathrm{Gray}\left(\mathrm{SiO}_{2}\right)-1,5 \mathrm{~V} / \mathrm{Gray}\left(\mathrm{SiO}_{2}\right)$. La linéarité et la stabilité de la réponse est satisfaisante.
\end{abstract}

\begin{abstract}
MOS transistors are used for radiation dosimetry. The sensitivity obtained is ranging between $20 \mathrm{mV} /$ Gray $\left(\mathrm{SiO}_{2}\right)$ and $1,5 \mathrm{~V} / \mathrm{Gray}\left(\mathrm{SiO}_{2}\right)$. Good linearity and stability of the transistor response is obtained.
\end{abstract}

\section{Introduction.}

The use of MOS transistors for the detection and dosimetry of ionizing radiation has been previously proposed in the literature [1-3]. This kind of detector has many advantages among which its low cost, the possibility it offers to make either real time or integrated measurement or its small size allowing precise dose mapping.

The dosimetry is made by measuring the charge stored during irradiation in the insulating layer of a MOS transistor and at the insulator semiconductor interface. For a given radiation dose the amount of stored charge depends upon the processing conditions and most often the goal of the work published upon this dependence was directed to minimize the radiation effects (hardening of the device). At the opposite the objective here is to increase these effects. However up to now the properties of the transistors have not been optimized for this purpose and consequently the potentialities of the MOS transistor as a radiation dosimeter are not well known. As an example the maximum sensitivity published up to now is about $0.85 \mathrm{~V} / \mathrm{Gray}\left(\mathrm{SiO}_{2}\right)$ [4].

In this paper we recall briefly the technological process used in order to optimize the sensitivity of the device to irradiation as well as its stability with time. The detailed process flow issued from an analysis of the results in the literature and from our own experience has been given already [5].

Then the electrical properties of the dosimeters are presented. Mainly the linearity and sensitivity are emphasized.

\section{Technological process.}

The technological process is the following : $\langle 100\rangle$ p-type $1-2 \Omega . \mathrm{cm}$ silicon substrate has been oxidized in dual steam/dry $\mathrm{O}_{2}$ ambient in order to obtain a field oxide with thickness ranging between 0.5 and $1 \mu \mathrm{m}$ depending upon the gate oxide thickness. Then patterning and diffusion of both source and drain are performed. Phosphorus is deposited from a $\mathrm{POCl}_{3}$ source at $1050^{\circ} \mathrm{C}$ and subsequently driven in steam at $1050^{\circ} \mathrm{C}$ during $5 \mathrm{~min}$. The gate oxide is then patterned, grown at $1150^{\circ} \mathrm{C}$ in dry $\mathrm{O}_{2}$ and annealed in situ at the same temperature in argon during $15 \mathrm{~min}$. The obtained oxide thickness is ranging between $1000 \AA$ and $3000 \AA$. Then contacts are defined and chromium is deposited by thermal evaporation. Drain, source and gate electrodes are defined. The same process but with removing the field oxide on the whole wafer before gate oxidation has been used to obtain devices with $5000 \AA$ and $7000 \AA$ thick gate oxide layers. Together with the transistors capacitors have also been fabricated on the same substrate.

\section{Influence of irradiation.}

3.1 Calibration of the $\gamma$ and X-RAY SOURCes. Irradiation of the devices has been made by exposure either to a $\mathrm{Co}^{60} \gamma$ source or to a $150 \mathrm{kV} \mathrm{X}$-ray generator. The calibration in Gray $\left(\mathrm{SiO}_{2}\right)$ of the $\mathrm{Co}^{60}$ source has been performed through a Fricke's dosimetry [6] corrected for the mass energy absorption coefficient $\mu / \rho$. 
Because the X-ray generator does not deliver a monoenergetic beam it has been first calibrated in Gray (air) by irradiation and analysis of $\mathrm{B}_{4} \mathrm{O}_{7} \mathrm{Li}_{2}(\mathrm{Cu})$ thermoluminescent detector [7]. Then the conversion in Gray $\left(\mathrm{SiO}_{2}\right)$ has been obtained by adjusting the sensitivity $S$ of a MOS transistor at infinite electric field for X-ray to the one for $\mathrm{Co}^{60}$ with the aid of the curves $1 / S\left(\mathrm{Co}^{60}\right)\left(\mathrm{Gray}\left(\mathrm{SiO}_{2}\right) / \mathrm{mV}\right)$ and $1 / \mathrm{S}(\mathrm{X}$-ray) (Gray(air)/mV) versus the reciprocal of the electric field during irradiation $E_{\text {ir }}[8]$.

An example of the obtained curves is shown in figure 1 . The good linearity obtained confirms the recombination model proposed by Brown and Dozier [9].

Within their model the initial hole density $p_{\mathrm{i}}$ in the cloud of carriers created by the impinging particle and its value $p_{\mathrm{f}}$ after a duration during which the electron and hole distributions overlapp are linked by the relation :

$$
p_{\mathrm{f}}^{-1}=p_{\mathrm{i}}^{-1}+\frac{\alpha}{E_{\mathrm{ir}}}
$$

where $\alpha$ is a constant.

Consequently the probability $f\left(E_{\mathrm{ir}}\right)$ for a hole to escape recombination is given by :

$$
1 / f\left(E_{\mathrm{ir}}\right)=\frac{p_{\mathrm{i}}}{p_{\mathrm{f}}}=1+\frac{\alpha}{E_{\mathrm{ir}}} p_{\mathrm{i}} .
$$

Neglecting interface state generation during irradiation and making the hypothesis of a storage of the created holes in a thin sheet at a distance $X_{\mathrm{c}}$ from the $\mathrm{SiO}_{2}-\mathrm{Si}$ interface the threshold voltage shift with gate positively biased can be written [10] :

$$
\Delta V_{\text {TO }}=\frac{-q g}{\varepsilon_{0} \varepsilon_{\mathrm{ox}}} f\left(E_{\mathrm{ir}}\right) \cdot f_{\mathrm{t}} \cdot D\left(D_{\mathrm{ox}}-X_{\mathrm{c}}\right)^{2}
$$

where $\varepsilon_{0}$ is the permittivity of vacuum, $\varepsilon_{\mathrm{ox}}$ the dielectric constant for silica, $D$ the radiation dose, $f_{t}$ the probability for a hole to be trapped in the sheet, $q$ the electron charge, $g$ the electron-hole pair generation rate equal to $7.9 \times 10^{12} \mathrm{~cm}^{-3} / \mathrm{Gray}\left(\mathrm{SiO}_{2}\right)[10]$ and $D_{\text {ox }}$ the thickness of the oxide layer.

From (3) the sensitivity $S$, defined as $\frac{\left|\Delta V_{\mathrm{TO}}\right|}{D}$, can be written

$$
\frac{1}{S}=\frac{1}{S_{\mathrm{m}}}+\frac{A}{E_{\mathrm{ir}}}=\frac{1+\alpha p_{\mathrm{i}} / E_{\mathrm{ir}}}{\frac{q g}{\varepsilon_{0} \varepsilon_{\mathrm{ox}}} f_{\mathrm{t}}\left(D_{\mathrm{ox}}-X_{\mathrm{c}}\right)^{2}} .
$$

Consequently it appears from (4) that the sensitivity at infinite electric field $S_{\mathrm{m}}$ is independent of the type and energy of the incident particle.

So any difference between $S_{\mathrm{m}}^{\mathrm{C}_{0} 60}$ expressed in Gray $\left(\mathrm{SiO}_{2}\right)$ and $S_{\mathrm{m}}^{\mathrm{RX}}$ expressed in Gray(air) must be attributed to the mass-energy absorption coefficients

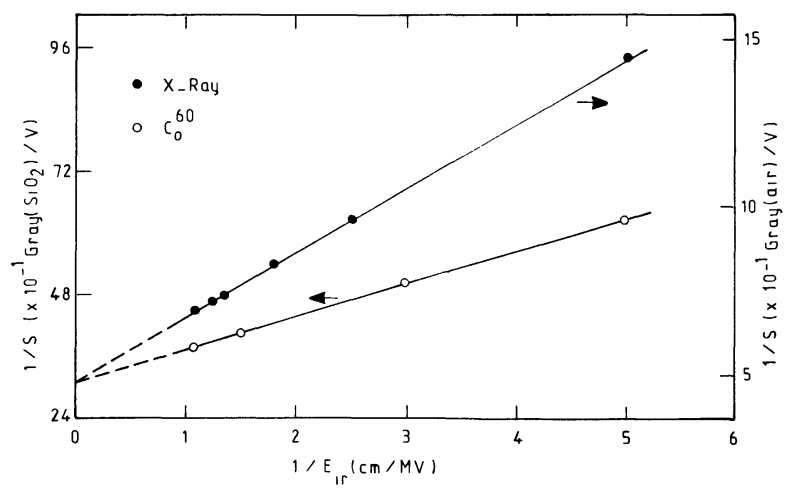

Fig. 1. - Variation of the reciprocal of the sensitivity $S$ with the reciprocal of the electric field $E_{\mathrm{ir}}-\left(D_{\mathrm{ox}}=3000 \AA\right)$.

ratio $\theta_{\mathrm{RX}}$ for X-ray such that :

$$
\theta_{\mathrm{RX}}=\frac{D \mathrm{Gray}\left(\mathrm{SiO}_{2}\right)}{D \mathrm{Gray}(\text { air })} \text {. }
$$

3.2 GeNERAL ELECTRICAL CHARACTERISTICS. Figure 2 shows the response of the transistor as a function of the received dose. The curves are characterized by a linear part at low dose followed by a saturation region. This behaviour has been observed whatever is the oxide layer thickness.

The saturation value has been found proportional to the voltage $V_{\text {Girr }}$ applied on the gate for electric field in the oxide lower than $1 \mathrm{MV} \mathrm{cm}{ }^{-1}$. An example of the variation of the maximum threshold voltage shift $\Delta V_{\mathrm{T} \max }$ versus $V_{\text {Girr }}$ is shown in figure 3.

This proportionality indicates that the saturation occurs because of a zero electric field in the oxide layer [10]. Furthermore the slope of the curve gives the value of the centroid of the trapped charge [9].

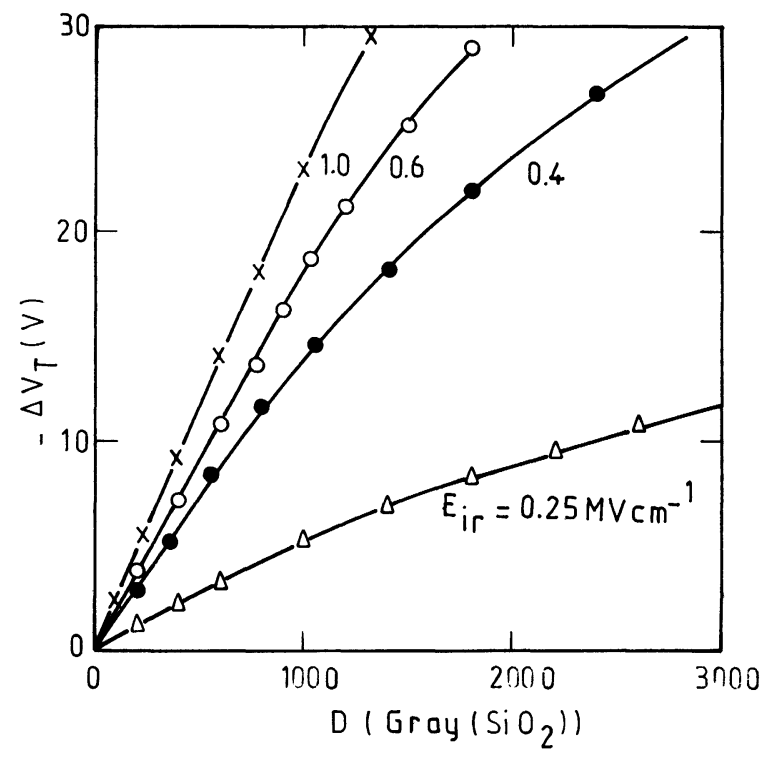

Fig. 2. - Influence of the irradiation dose $D$ on the threshold voltage shift $\Delta V_{\mathrm{T} \cdot}\left(D_{\mathrm{ox}}=1000 \AA\right.$. $)$ 


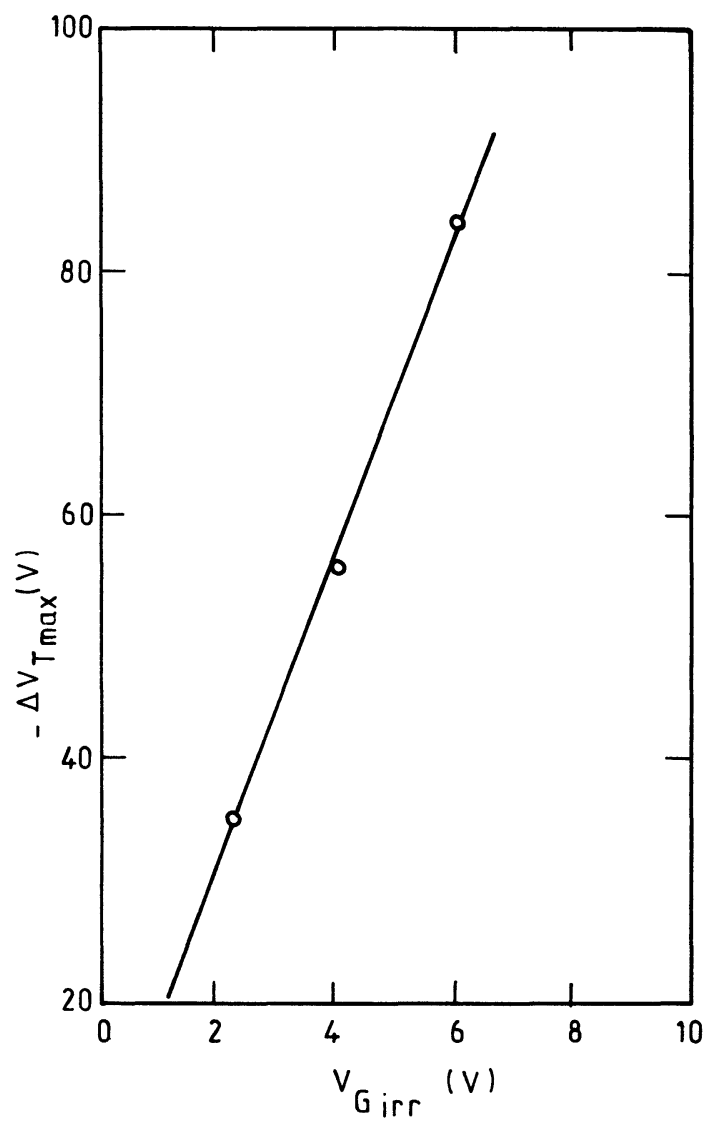

Fig. 3. - Influence of the gate bias $V_{\text {Girr }}$ upon the maximum threshold voltage shift for three values of $E_{\mathrm{ir}}-\left(D_{\mathrm{ox}}=\right.$ $1000 \AA)$.

A mean value of $X_{\mathrm{C}}=65 \AA$ is obtained in agreement with previous results [11].

3.3 INFLUENCE OF THE VOLTAGE APPLIED ON THE GATE. - The extension of the linear part of the curve at low dose is increasing with the applied bias. If this extension is defined as the dose $D_{\mathrm{L}}$ for which the experimental curve deviates $5 \%$ from the linear curve, its variation with the applied voltage is represented in figure 4 in the case where $D_{0 x}=1000 \AA$. As it can be seen increasing the applied voltage has a large beneficial influence.

Another benefit concerns the sensitivity of the MOS transistor. As shown in figure 2 the sensitivity of the device defined as the slope of the linear part of the curve increases greatly with the gate voltage.

As it has been recalled before, this influence is due to the dependence of the probability for a hole to escape recombination upon the electric field $E_{\mathrm{ir}}$. The variation of $f\left(E_{\mathrm{ir}}\right)$ versus $E_{\mathrm{ir}}$ obtained experimentally from curves similar to those shown in figure 1 through the relation :

$$
f\left(E_{\mathrm{ir}}\right)=\frac{1}{1+\frac{S_{\mathrm{m}} A}{E_{\mathrm{ir}}}}
$$

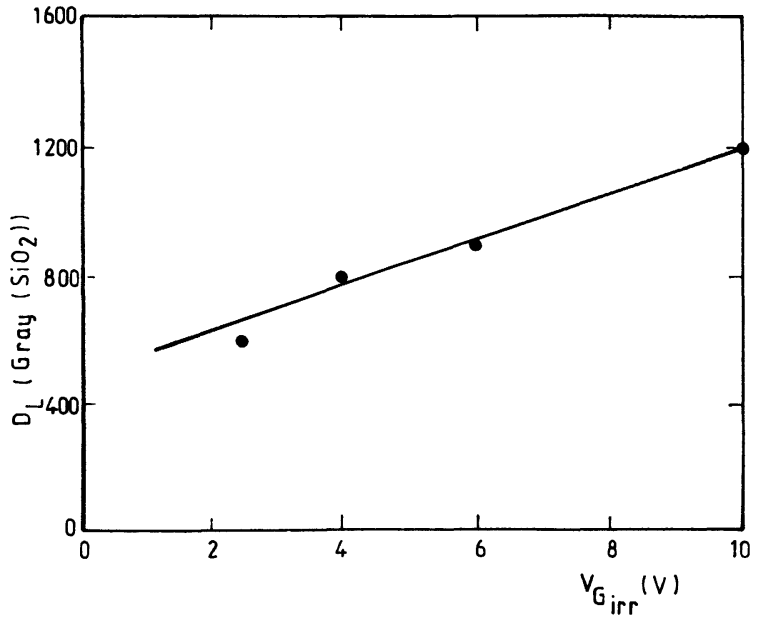

Fig. 4. - Extension of the linear region versus the gate bias $V_{\text {Girr }}$ during irradiation. $\left(D_{\mathrm{ox}}=1000 \AA\right.$.)

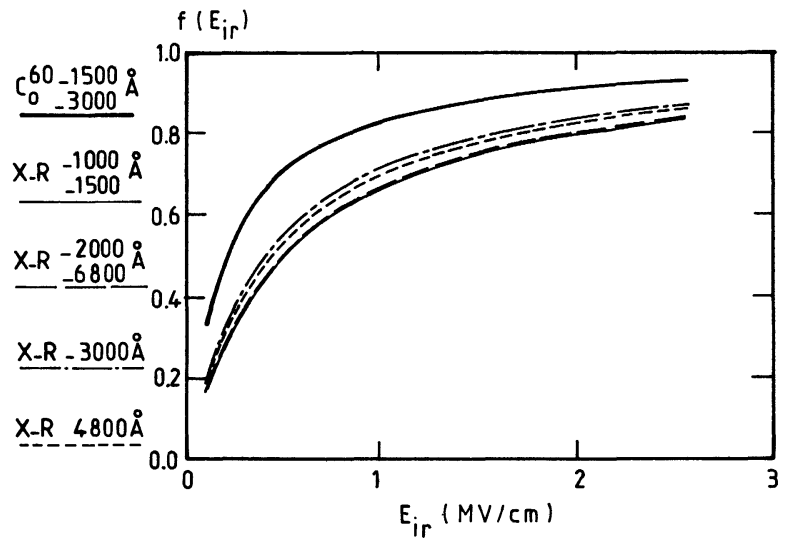

Fig. 5. - Probability to escape recombination for electrons versus the electric field $E_{\mathrm{ir}}$.

is shown in figure 5 . It appears that under $1 \mathrm{MV} / \mathrm{cm}$ $f\left(E_{\mathrm{ir}}\right)$ increases rapidly with the electric field and increases slightly above $1 \mathrm{MV} / \mathrm{cm}$.

A negative influence of the gate voltage affects the stability of the device with time. This parameter is very important as far as integrated dose or low dose rate [12] are concerned.

Indeed irradiation creates a negative shift of the threshold voltage. After irradiation $V_{\mathrm{T}}$ evoluates back with time towards more positive values. This recovery has been shown to depend upon the insulator thickness and the gate voltage.

Because this effect can be present even during the exposure it must be minimized in order to improve the performances of the dosimeter.

The relative amplitude of the positive post-irradiation recovery is depicted in figure 6 as a function of time and the influence of the gate voltage is clearly shown. 


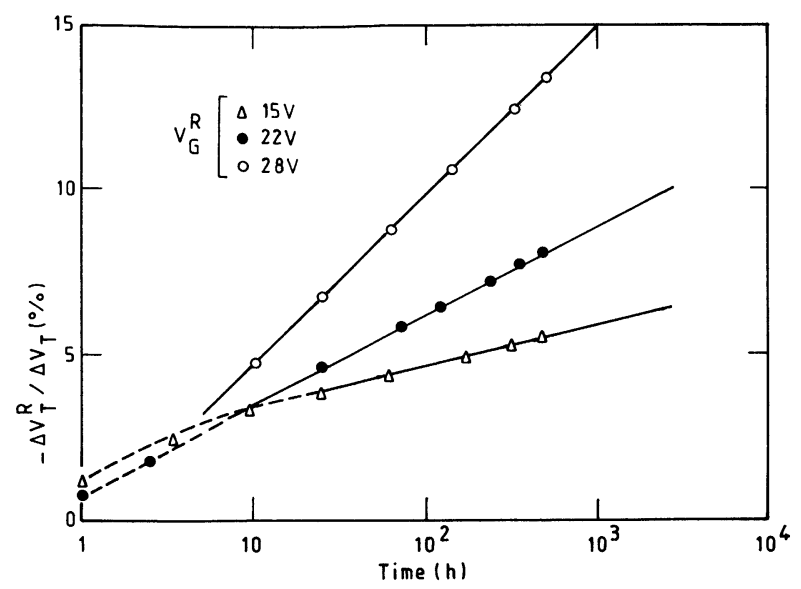

Fig. 6. - Relative amplitude of the post-irradiation recovery $\Delta V_{\mathrm{T}}^{\mathrm{R}}$ versus time. $\left(D_{\mathrm{ox}}=1500 \AA\right)$-ambient temperature.

So there is a compromise to reach between sensitivity and stability. Figure 5 shows that increasing the gate electric field beyond $1 \mathrm{MV} / \mathrm{cm}$ induces a small sensitivity gain whatever is the oxide layer thickness whereas figure 6 does not show any saturation beyond $1 \mathrm{MV} / \mathrm{cm}$. Consequently applying a gate voltage in order to obtain a $1 \mathrm{MV} / \mathrm{cm}$ electric field in the oxide layer appears a good compromise. On the other hand this value is less than the mean breakdown field of the oxide which has been found constant and equal to $7.5 \mathrm{MV} / \mathrm{cm}$ as shown in figure 7 .

3.4 INFLUENCE OF THE OXIDE LAYER THICKNESS. The oxide layer thickness is known as a key parameter which controls the sensitivity of the transistor. Its influence has been examined in the range $1000 \AA$ $7000 \AA$. Figure 8 shows the threshold voltage shift as a function of the dose with a $1 \mathrm{MV} / \mathrm{cm}$ electric field in the oxide during irradiation.

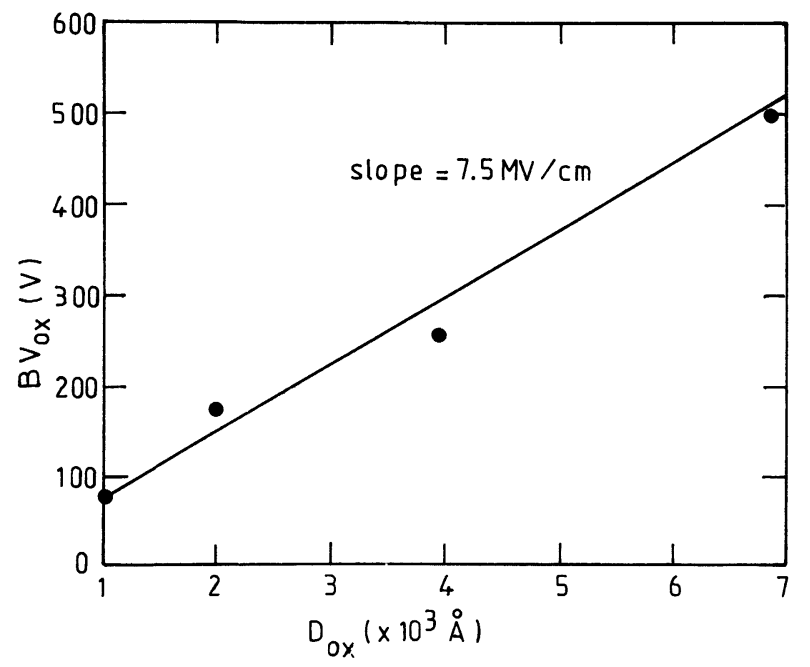

Fig. 7. - Mean value of the observed breakdown voltage of the oxide layer versus the thickness $D_{\text {ox }}$.

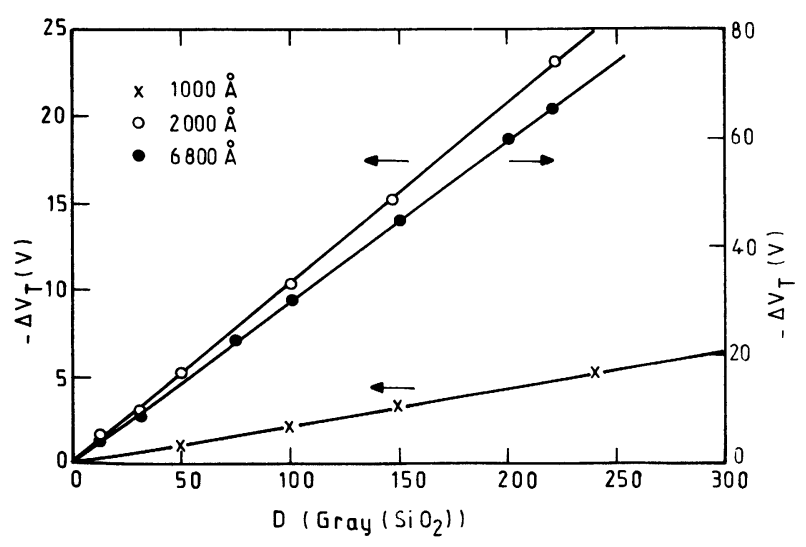

Fig. 8. - Threshold voltage shift versus irradiation dose as a function of $D_{\text {ox }}$.

It can be seen that the linearity is maintained within the whole range.

The sensitivity increases rapidly with $D_{\text {ox }}$ and as shown in figure 9 it varies as $D_{\text {ox }}^{n}$ with $n$ very close to two in agreement with relation (3).

This agreement shows that both dose enhancement effect and interface state generation have a small influence.

Another argument for neglecting the first effect is that the $\mathrm{Co}^{60}$ and X-Ray curves in figure 9 are parallel with $S\left(\mathrm{Co}^{60}\right)>S$ (X-Ray).

Indeed dose enhancement does not occur with $\mathrm{Co}^{60}$ irradiation and it has been shown [4] that enhancement occurs mainly for small thicknesses.

As far as the stability is concerned figure 10 shows that increasing the oxide layer thickness has a beneficial effect on the post-irradiation recovery. For thicknesses larger than $5000 \AA$ the shift has not been detectable.

\section{Sensitivity of the oxide layer.}

The sensitivity of the oxide layer to irradiation is a function of $D_{\mathrm{ox}}, f\left(E_{\mathrm{rr}}\right)$ and $f_{\mathrm{t}}$. In order to test the degree of optimization of the technological process it is necessary to determine the value of $f_{t}$.

This can be done from the curve $S=f\left(D_{\mathrm{ox}}^{2}\right)$. As far as $D_{\mathrm{ox}} \gg X_{\mathrm{o}_{1}}$ the slope of this curve is given by :

$$
\text { slope }=\frac{q g}{\varepsilon_{0} \varepsilon_{\mathrm{ox}}} f_{\mathrm{t}} . f\left(E_{\mathrm{ir}}\right) .
$$

Taking into account the value of $f\left(E_{\mathrm{ir}}\right)$ for $E_{\mathrm{ir}}=$ $1 \mathrm{MV} / \mathrm{cm}$ gives $f_{\mathrm{t}}=0.97$ for $\mathrm{Co}^{60}$ irradiation and $1.04-1.09$ for X-rays.

Of course $f_{\mathrm{t}}$ cannot be greater than one. The excess value for X-ray may be due to a small dose enhancement. More probably, this is due to experimental errors associated with instabilities of our X-ray generator. However the values very close to one for both $\mathrm{Co}^{60}$ and X-ray show that the technological process is satisfactorily optimized in view of a high sensitivity. 


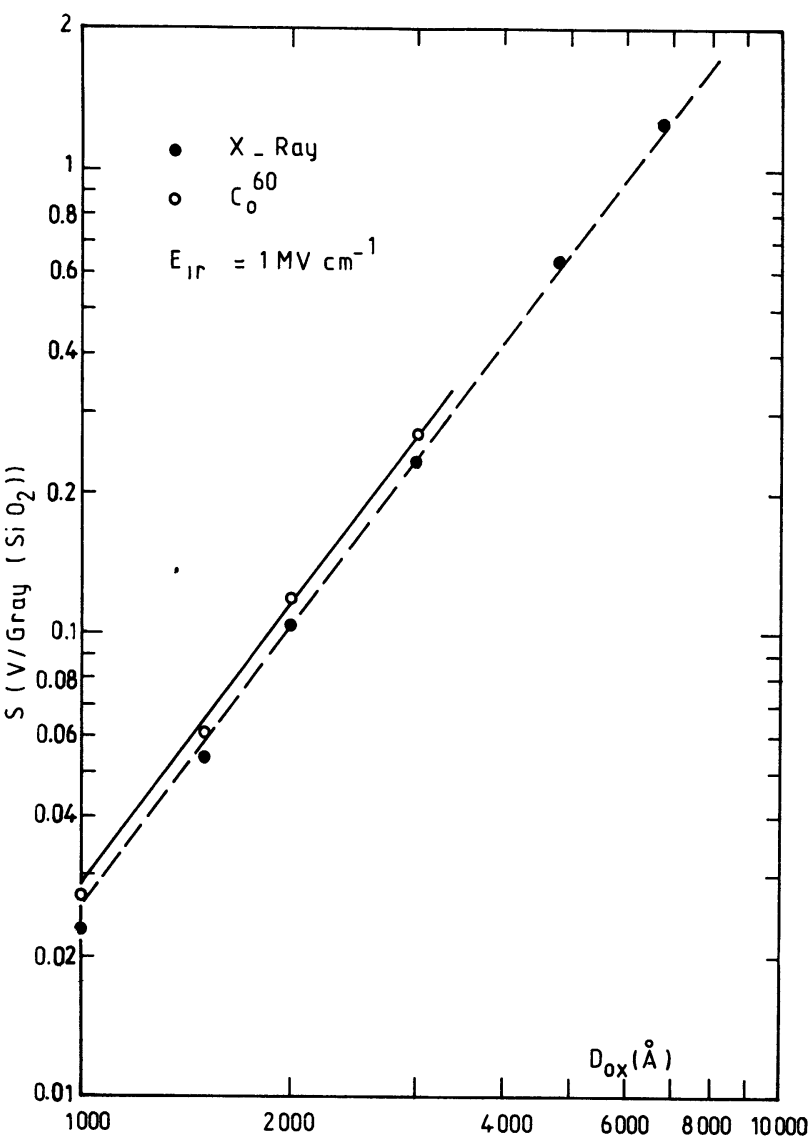

Fig. 9. - Influence of the oxide layer thickness on the sensitivity to irradiation dose.

\section{Conclusion.}

In this paper we have shown that MOS transistors can be used as ionizing radiation dosimeter with good linearity and stability and with a sensitivity as high as $1.5 \mathrm{~V} / \mathrm{Gray}\left(\mathrm{SiO}_{2}\right)$. The technological process has been found satisfactorily optimized leading to a value very close to one for the probability that a created hole be trapped near the $\mathrm{SiO}_{2}-\mathrm{Si}$ interface.

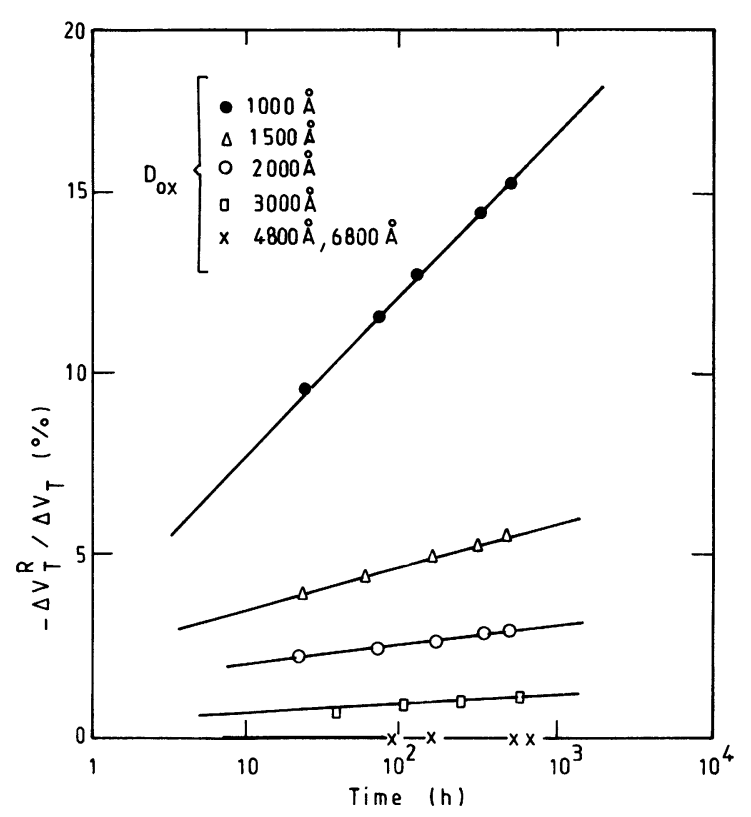

Fig. 10. - Influence of the insulating layer thickness on the post-irradiation recovery. Electric field in the oxide during recovery : $1 \mathrm{MV} / \mathrm{cm}$.

The general behaviour of the dosimeter is consistent with a first order theoretical analysis and no experimental limitation has been found for the sensitivity.

Work is now in progress to evaluate the stability of MOS transistors with an oxide layer thicker than $1 \mu \mathrm{m}$.

\section{Acknowledgments.}

The authors acknowledge the skillful assistance of F. Rossel and T. Do Conto for fabricating the devices and $L$. Thores and S. Lorrain for irradiating the samples.

\section{References}

[1] Adams, L. and Holmes-Siedle, A. G., IEEE Trans. Nucl. Sci. NS 25, 6, (1978) 1607.

[2] August, L. S., IEEE Trans. Nucl. Sci. NS 29, 6 (1982) 2000.

[3] Frankand, H. and Petr,.I., Jaderna Energie 23, 7 (1977) 258.

[4] Oldtram, T. R. and MacGarritv, J. M., IEEE Trans. Nucl. Sci. NS 30, 6 (1983) 4377.

[5] Bellaouar, A., Sarrabayrouse, G. and Rossel, P., 13th Yougoslav Conference on Microelectronics (MIEL 85). Ljubljana, 8-10 May 1985.

[6] El Dessouky, A., Contribution à l'étude de la Radiolyse des cétones fréryliques dans le propanol, Thèse de 3e Cycle, No 159, Université de Toulouse III, 1982.

[7] KATZ, E. B., Application de la dosimétrie par $R T L \grave{a}$ l'étude expérimentale de l'indice équivalent de dose, Thèse No 2421, Université de Toulouse III, 1980.

[8] DorIE, C. M. and Brown, D. B., IEEE Trans. Nucl. Sci. NS 28, 6 (1981) 4137.

[9] Brown, D. B. and DozIER, C. M., IEEE Trans. Nucl. Sci. NS 28, 6 (1981) 4142.

[10] Holmes Siedle, A. G. and Freeman, R., Radiation effect Engineering handbook, ESA Report № 2871/ 76/NL/HP, April 1978.

[11] Curtis, J. L., Srour, J. R. and Chiu, K. Y., J. Appl. Phys. 45 (1974) 4506.

[12] Sarrabayrouse, G., Bellaouar, A. and Rossel, P., Dérives temporelles post-irradiation dans les dosimètres MOS de rayonnement (to be published). 